of purine metabolism characterized by hypotonia followed by spasticity, chorea, athetosis, dystonia, growth and mental retardation, self-mutilatory behavior, hyperuricemia, and nephrolithiasis (Lesch M, Nyhan WL. AM J Med 1964;36:561). The phenotypical expression is the result of a deficiency of hypoxanthineguanine phosphoribosyl-transferase enzyme, the gene located on the long arm of the $\mathrm{x}$ chromosome. Response to medications is variable but self-mutilation can sometimes be ameliorated (Herman $\mathrm{BH}$ et al. Naltrexone decreases self-injurious behavior. Ann Neurol $1987 ; 22: 550$ ).

\title{
INIRACRANIAL TUMORS
}

NEONATAL CRANIOPHARYNGIOMA

A craniopharyngioma detected in utero using ultrasound is reported from the Depts of Neurosurgery, Neonatology, Pathology, and Obstetrics and Gynecology, New York University Medical Center, New York, NY. The obstetric ultrasound study performed because of premature labor at 35 weeks showed polyhydramios and macrocephaly secondary to an intracranial, calcified lobulated mass. A CT scan performed at $2 \mathrm{hrs}$. of life demonstrated a calcified intracranial mass extending to the base of the skull. The infant suffered cardiorespiratory arrest and died at the second day of life. At postmortem examination, the suprasellar mass was a granular tumor with multiple cysts filled with green mucoid material. Microscopically, the tumor showed branching cords and pallisading of epithelial cells, focal calcifications, and an inner zone of stellate cells, an appearance diagnostic of craniopharyngioma. The authors uncovered only four other reports of congenital intracranial neoplasms diagnosed prenatally using ultrasound. Three were teratomas and one a dysplastic mass. Calcifications have been observed in teratomas and meningiomas in utero and are not pathognomonic of craniopharyngioma. Low set ears and polydactyly are reported as associated congenital anomalies. Polyhydramnios occurred in all five cases of neonatal brain tumors diagnosed antenatally by ultrasound. Radical excision of the tumor in the neonatal period was not advised. (Freeman TB et al. Neonatal cranipharyngioma. NY State J Med Feb 1988;88:81-83).

COMMENT: Craniopharhngiomas comprise about $3 \%$ of all intracranial tumors at all ages and $9 \%$ in children. Only 10 cases of neonatal craniopharyngioma were culled from the literature. Radical excision for cases presenting in infancy is recommended by the following authors reporting their experiences with 50 cases in Paris.

\section{TREATMENT OF CRANIOPHARYNGIOMA IN INFANCY}

A retrospective analysis of the outcome of 50 cases of craniopharyngioma treated in infancy by radical or subtotal surgical excision and irradiation is reported from the Services of Neurosurgery and Endocrinology, Hopital des Enfants Malades, 149, reu de Sevres, 75743 Paris Cedex 15, France. The authors concluded that 1) radical excision is the treatment of choice; 2) if radical excision is not possible, surgery should be followed by irradiation to lower risk of recurrence; and 3 ) radiotherapy should be delayed as long as possible because of hazards to 